\title{
In Vitro Ischemic Tolerance Involves Upregulation of Glutamate Transport Partly Mediated by the TACE/ADAM17-Tumor Necrosis Factor- $\alpha$ Pathway
}

\author{
Cristina Romera, ${ }^{1}$ Olivia Hurtado, ${ }^{1}$ Sofia H. Botella, ${ }^{1}$ Ignacio Lizasoain, ${ }^{1}$ Antonio Cárdenas, ${ }^{1}$ Paz Fernández-Tomé, ${ }^{2}$ \\ Juan C. Leza, ${ }^{1}$ Pedro Lorenzo, ${ }^{1}$ and Maria A. Moro ${ }^{1}$ \\ ${ }^{1}$ Departamento de Farmacología and ${ }^{2}$ Instituto Mixto de Farmacología-Toxicología, Consejo Superior de Investigaciones Científicas, Facultad de Medicina, \\ Universidad Complutense de Madrid, 28040 Madrid, Spain
}

\begin{abstract}
A short ischemic event [ischemic preconditioning (IPC)] can result in a subsequent resistance to severe ischemic injury (ischemic tolerance). Although tumor necrosis factor- $\alpha$ (TNF- $\alpha$ ) contributes to the brain damage found after cerebral ischemia, its expression and neuroprotective role in models of IPC have also been described. Regarding the role of TNF- $\alpha$ convertase (TACE/ADAM17), we have recently shown its upregulation in rat brain after IPC induced by transient middle cerebral artery occlusion and that subsequent TNF- $\alpha$ release accounts for at least part of the neuroprotection found in this model. We have now used an in vitro model of IPC using rat cortical cultures exposed to sublethal oxygen-glucose deprivation (OGD) to investigate TACE expression and activity after IPC and the subsequent mechanisms of ischemic tolerance. OGD-induced cell death was significantly reduced in cells exposed to IPC by sublethal OGD 24 $\mathrm{hr}$ before, an effect that was inhibited by the TACE inhibitor BB3103 (1 $\mu \mathrm{M})$ and anti-TNF- $\alpha$ antibody $(2 \mu \mathrm{g} / \mathrm{ml})$ and that was mimicked by TNF- $\alpha(10 \mathrm{pg} / \mathrm{ml})$ preincubation. Western blot analysis showed that TACE expression is increased after IPC. IPC caused TNF- $\alpha$ release, an effect that was blocked by the selective TACE inhibitor BB-3103. In addition, IPC diminished the increase in extracellular glutamate caused by OGD and increased cellular glutamate uptake and expression of EAAT2 and EAAT3 glutamate transporters; however, only EAAT3 upregulation was mediated by increased TNF- $\alpha$. These data demonstrate that neuroprotection induced by IPC involves upregulation of glutamate uptake partly mediated by TACE overexpression.
\end{abstract}

Key words: cerebral ischemia; ischemic preconditioning; transporters; neuroprotection; stroke; TNF- $\alpha$

\section{Introduction}

Ischemic preconditioning (IPC) is an endogenous phenomenon in which brief periods of ischemia render a tissue more resistant to subsequent sustained loss of blood flow. Preconditioning can induce ischemic tolerance in a variety of organ systems including brain. Indeed, Kitagawa et al. (1990) found that gerbils subjected to sublethal transient global ischemia exhibited reduced hippocampal CA1 neuronal death after a more severe ischemic insult 24-48 hr later, and similar findings have been reported by others (for review, see Barone et al., 1998; Kirino, 2002). Ischemic tolerance also has been demonstrated in human clinical practice, because less severe strokes have been described in patients with prior ipsilateral transient ischemic attacks within a short period of time (Weih et al., 1999; Moncayo et al., 2000; Castillo et al.,

Received July 2, 2003; revised Dec. 2, 2003; accepted Dec. 4, 2003.

This work was supported by Spanish Ministries of Science and Technology and Health Grants SAF2002-04487C02-01 (I.L.) and BI02000-0405-P4-05 (P.L.) and by Local Madrid Government (Comunidad Autónoma de Madrid) reference $08.5 / 0077.1 / 2000$ (P.L.). C.R. and 0.H. are recipients of fellowships funded by MSC-FIS-01.650 and Ferrer $S A$, respectively. We are greatly indebted to Jose Miguel Ruiz for technical support.

Correspondence should be addressed to Dr. Maria A. Moro, Departamento de Farmacología, Facultad de Medicina, Universidad Complutense, 28040 Madrid, Spain. E-mail: neurona@med.ucm.es. DOI:10.1523/JNEUROSCI.1596-03.2004

Copyright $\odot 2004$ Society for Neuroscience $\quad$ 0270-6474/04/241350-08\$15.00/0
2003). The remarkable protection induced by IPC makes this an attractive target for potential therapeutic development.

As possible underlying molecular mechanisms, a great variety of mediators have been postulated: induction of heat shock proteins (Kirino et al., 1991), NMDA receptors (Kato et al., 1992; Kasischke et al., 1996; Grabb and Choi, 1999), antiapoptotic factors (Shimazaki et al., 1994), interleukin-1 (Ohtsuki et al., 1996), adenosine receptors and ATP-dependent potassium channels (Heurteaux et al., 1995), superoxide dismutase (Toyoda et al., 1997), reactive oxygen species (Ravati et al., 2001), nitric oxidedependent p $21^{\text {ras }}$ activation (González-Zulueta et al., 2000), metallothioneins (Trendelenburg et al., 2002), activation of vascular endothelial growth factor receptor and Akt (Wick et al., 2002), erythropoietin (Ruscher et al., 2002), and caspase-3 (McLaughlin et al., 2003). In addition, the activation of transcription factors such as nuclear factor- $\kappa \mathrm{B}$ has been implicated recently by several authors in the development of ischemic tolerance (Blondeau et al., 2001; Ginis et al., 2002). This factor plays a pivotal role in neuronal survival and is activated by various signals like proinflammatory cytokines, neurotrophic factors, and neurotransmitters (for review, see Mattson et al., 2000).

Tumor necrosis factor- $\alpha$ (TNF- $\alpha)$ has been implicated in both detrimental and neuroprotective mechanisms of ischemic injury (for review, see Barone and Feuerstein, 1999; Shohami et 
al., 1999; Del Zoppo et al., 2000; Hallenbeck, 2002). Regarding its neuroprotective role, some studies have demonstrated that TNF- $\alpha$ is a key mediator in IPC as well (Liu et al., 2000; Wang et al., 2000).

TNF- $\alpha$ is shed in its soluble form by a membrane-anchored zinc protease, identified as a disintegrin and metalloproteinase (ADAM) called TNF- $\alpha$ convertase (TACE/ADAM17). We have demonstrated recently, using in vitro models, that TACE is upregulated after ischemic brain damage and that the increase in TACE expression contributes to a rise in TNF- $\alpha$ and a subsequent neuroprotective effect after excitotoxic stimuli (Hurtado et al., 2001, 2002). Moreover, we have recently shown TACE upregulation after IPC, its major role in TNF- $\alpha$ shedding in this setting, and its neuroprotective role in ischemic tolerance (Cárdenas et al., 2002).

We have now decided to investigate the mechanisms involved in TACE-induced neuroprotection in ischemic tolerance by using rat cortical cultures exposed to sublethal oxygen-glucose deprivation as IPC.

\section{Materials and Methods}

Primary culture of rat cortical cells. All experimental protocols adhered to the guidelines of the Animal Welfare Committee of the Universidad Complutense (following DC 86/609/EU). Primary cultures of mixed cortical cells were performed as described previously (Hurtado et al., 2002), by removing brains from fetal Wistar rats at embryonic day (E) 18 and dissecting the cortical area. For pure neuronal cultures, fetal Wistar rats were used at E16. The rationale for choosing E18 or E16 is based on the fact that generation of cortical cell types occurs in temporally distinct, albeit overlapping, phases. In rats, the ventricular zone (VZ) arises first, and cells from this area develop mainly into neurons. VZ neurogenesis peaks at E14 and recedes at E17, whereas cells originating from the subventricular zone at late embryonic days and early postnatal life [rat E17 to postnatal day (P) 14] are destined predominantly for glial lineages (for review, see Sauvageot and Stiles, 2002). Cells were dissociated mechanically in incubation medium consisting of Eagle's MEM containing $33 \mathrm{~mm}$ glucose, $2 \mathrm{~mm}$ glutamine, $16 \mathrm{mg} / \mathrm{l}$ gentamicin, $10 \%$ horse serum (HS), and $10 \%$ FCS [growth medium (GM)]. The dissociated cells were plated at a density of $3 \times 10^{5}$ cells per $\mathrm{cm}^{2}$ in poly-lysine-precoated 6-, 12-, or 24-multiwell plates. Plates were kept in a $37^{\circ} \mathrm{C}$ incubator in a humidified atmosphere containing $95 \% \mathrm{O}_{2} / 5 \% \mathrm{CO}_{2}$. On day 4, medium was changed to fresh GM lacking FCS and to which cytosine arabinoside (10 $\mu \mathrm{mol} / \mathrm{l}$ ) was added. Medium was replaced $3 \mathrm{~d}$ later to fresh GM lacking both FCS and cytosine arabinoside (normal medium). Studies were performed at in vitro days 9 and 10, the time at which the mixed cultures consisted of $60 \pm 10 \%$ neurons, as determined by flow cytometry (Hurtado et al., 2002). With the same procedure, the percentage of neurons in pure neuronal cultures was determined: cells were detached by trypsinization ( $0.025 \%$ trypsin and $0.02 \%$ EDTA in PBS), washed once in PBS, and then fixed for $30 \mathrm{~min}$ in a solution containing $4 \%$ paraformaldehyde in $0.1 \mathrm{~m}$ phosphate buffer, $\mathrm{pH} 7.4$, at room temperature. Then, cells were spun down at 13,000 rpm in a microcentrifuge (Hettich, Tuttlingen, Germany), and pellets were resuspended in PBS containing 3\% BSA and $0.2 \%$ Triton X-100 for $30 \mathrm{~min}$. Cells were washed and incubated $2 \mathrm{hr}$ at room temperature in a monoclonal anti-NeuN antibody (1:200 dilution; Chemicon, Temecula, CA) or a monoclonal anti-MAP2 antibody (1:200 dilution; Chemicon). After washing in PBS, cells were incubated in Cy2-labeled anti-mouse IgG (1:300 dilution; Amersham Pharmacia Biotech, Piscataway, NJ) for $1 \mathrm{hr}$. Cells were then analyzed in a FACScan flow cytometer (Becton-Dickinson, Mountain View, CA) connected to a MacIntosh Quadra II computer system to collect fluorescence from Cy2. For all studies, 10,000 cells were acquired per sample, and statistical analysis was made. Data were recorded and analyzed using the Cell Quest software program. The flow cytometer was checked daily with fluorescent beads to detect daily variations in the measurement. Studies were performed at in vitro days 9-10, the time at which these cultures consisted of $94 \pm 6 \%$ neurons.
Astrocyte culture. Primary astrocyte cultures were prepared from neonatal (P0) Wistar rat cortex, as described previously (McCarthy and de Vellis, 1980). Cells present in the culture were shown to be astrocytes ( $94 \pm 5 \%$ ) after characterization by flow cytometry, as described above, using a primary specific anti-GFAP antibody (1:100 dilution; Chemicon).

Neuronal-astrocyte coculture. On day 10 in culture, astrocytes were collected by trypsinization, resuspended, and plated at a density of $1.4 \times$ $10^{5}$ cells per $\mathrm{cm}^{2}$ in culture plate inserts $(1 \mu \mathrm{m}$ membrane pore size; 4.2 $\mathrm{cm}^{2}$ of effective membrane growth area; Falcon; Beckton Dickinson Labware, Franklin Lakes, NJ) in a total volume of $1.5 \mathrm{ml}$ of fresh astrocytic culture medium. One day after astrocyte plating, coinciding with pure neuronal culture day 7, neurons plated in 6-well companion plates (Falcon; Beckton Dickinson Labware) had their medium replaced, then astrocyte-containing inserts were transferred to these wells, and $2 \mathrm{ml}$ of normal medium was added. Cocultures were transferred to the normoxic incubator, and exposure to oxygen-glucose deprivation (OGD) was performed $24 \mathrm{hr}$ later.

Exposure of rat cortical cultures to OGD. OGD was performed as described (De Cristóbal et al., 2002; Hurtado et al., 2002). Culture medium was replaced by a solution containing $(\mathrm{mM}): 130 \mathrm{NaCl}, 5.4 \mathrm{KCl}, 1.8$ $\mathrm{CaCl}_{2}, 26 \mathrm{NaHCO}_{3}, 0.8 \mathrm{MgCl}_{2}, 1.18 \mathrm{NaH}_{2} \mathrm{PO}_{4}$, and $2 \% \mathrm{HS}$ bubbled with $95 \% \mathrm{~N}_{2} / 5 \% \mathrm{CO}_{2}$ for OGD cells (OGD solution). OGD cells were transferred to an anaerobic chamber (Forma Scientific, Hucoa Erloss, Spain) containing a gas mixture of $95 \% \mathrm{~N}_{2} / 5 \% \mathrm{CO}_{2}$ and humidified at $37^{\circ} \mathrm{C}$ and maintained at a constant pressure of 0.15 bar. The time of exposure to OGD was $145 \mathrm{~min}$. This time was selected from previous time-response experiments in which we observed that OGD-induced release of glutamate from intact cells initiated abruptly after 140-160 min of OGD and that this effect was followed ( $\sim 10$ min later) by cell lysis, characterized by the release of cytosolic components among which lactate dehydrogenase $(\mathrm{LDH})$ and also glutamate (secondary release of glutamate, from broken cells) are found. Therefore, when the experiment was aimed at the study of the effect of preconditioning on OGD-induced primary glutamate release from intact cells, which could be masked by the secondary release of glutamate from broken cells, we selected the experiments in which OGD had triggered the release of glutamate from intact cells but in which there were no lysed cells yet. It is not always possible to capture this precise time point, and, therefore, those experiments in which LDH release or staining with propidium iodide immediately after OGD was higher than that from control cultures were excluded, to discard glutamate release resulting from disrupted cells (De Cristóbal et al., 2002). This does not affect other parameters such as viability, glutamate uptake, or protein expression, which are studied without this selection procedure.

OGD was terminated by replacing the exposure medium with oxygenated MEM containing $0.6 \%$ glucose, $0.029 \%$ glutamine, $50 \mathrm{IU} / \mathrm{ml}$ penicillin, $50 \mu \mathrm{g} / \mathrm{ml}$ streptomycin, and 10\% HS (reperfusion medium) and was returned to the normoxic incubator. Control cultures in a solution identical to OGD solution but containing glucose ( $33 \mathrm{~mm}$; control solution) were kept in the normoxic incubator for the same time period as the OGD, and then the incubation solution was replaced with reperfusion buffer and cultures were returned to the normoxic incubator until the end of the experiment. Culture medium was collected at the times indicated for TNF- $\alpha$ determination.

For IPC, cortical cultures were deprived of oxygen-glucose for $20 \mathrm{~min}$ as described, an insult that did not induce neuronal death as measured by LDH release or phase-contrast microscopy, in agreement with previous results (Grabb and Choi, 1999). After that time, OGD solution was replaced by reperfusion medium, and cultures were returned to the incubator. Simulated reperfusion was performed, as indicated above, for 24 $\mathrm{hr}$, either in the absence or presence of BB3103 (1 $\mu \mathrm{M}$; British Biotech), a succinate-based hydroxamic acid compound that inhibits metalloproteinases that mediate ectodomain shedding (Ancuta et al., 1997; Middelhoven et al., 1997; Lammich et al., 1999), or neutralizing concentrations of anti-TNF- $\alpha(2 \mu \mathrm{g} / \mathrm{ml}$; Pepro Tech EC, UK). BB3103 was used because hydroxamate-based compounds are able to distinguish between other proteases that might cleave pro-TNF- $\alpha$ and TACE, because they are more potent against TACE $\left(\mathrm{IC}_{50}\right.$ values $\left.\sim 0.05-0.1 \mu \mathrm{M}\right)$ than against others 
such as ADAM10 or $\alpha$-secretase $\left(\mathrm{IC}_{50}\right.$ values ranging from 3 to $>20 \mu \mathrm{M}$ ) (Parvathy et al., 1998; Hooper et al., 2000). Indeed, BB3103 is a preferred inhibitor of metalloproteinases with sheddase activity (Ancuta et al., 1997; Middelhoven et al., 1997; Fiorucci et al., 1998; Lammich et al., 1999 ) that shows an $\mathrm{IC}_{50}$ value of $\sim 0.1 \mu \mathrm{M}$ to inhibit OGD-induced TNF- $\alpha$ production in rat cortical cultures as well as in rat forebrain slices (Hurtado et al., 2001, 2002). In addition, other metalloproteases that could be targets of BB3103, such as matrix metalloproteases (MMPs), are unlikely to contribute because MMP activity found in this culture is very low (Hurtado et al., 2002). In some experiments, cortical cultures were incubated with TNF- $\alpha$ (10 pg/ml; Pepro Tech EC) for $24 \mathrm{hr}$. At this concentration, TNF- $\alpha$ did not affect cell viability. In addition, control experiments were performed in which cells were incubated for $24 \mathrm{hr}$ with BB3103 or anti-TNF- $\alpha$ to check their effect on cell viability.

Astrocyte-neuron cocultures were similarly exposed to sublethal OGD for $20 \mathrm{~min}$, followed by a $24 \mathrm{hr}$ period in reperfusion medium as described above.

Assessment of cell viability. As a marker of necrotic tissue damage, $\mathrm{LDH}$ activity released from damaged cells was determined. Culture medium and lysate from $0.1 \%$ Triton X-100 in PBS were collected $24 \mathrm{hr}$ after the OGD period. LDH activity was measured spectrophotometrically at 340 $\mathrm{nm}$ by following the oxidation of NADH (decrease in absorbance) in the presence of pyruvate (Koh and Choi, 1987) using a Thermomax microplate reader (Molecular Devices, Palo Alto, CA) or a DU7500 spectrophotometer (Beckman, Fullerton, CA). LDH release is expressed as the percentage of total cell $\mathrm{LDH}$ and is plotted as the percentage of $\mathrm{LDH}$ release induced by OGD. Basal LDH release was $6 \pm 1 \%(n=12)$.

In addition, viability was determined by morphological criteria after examining the cells under phase-contrast microscopy (Eclipse TE300 fluorescence microscope; Nikon, Tokyo, Japan) using a Plan Fluor $40 \times 1$ 0.6 objective and phase optics. Neurons with fragmented neurites and vacuolated soma were considered nonviable, whereas neurons with intact neurites and a cell body that was smooth and round to oval in shape were considered viable. The counting was performed by placing a counting grid in the microscope ocular to count cell numbers from four random fields for each group. Each experiment was performed in duplicate and repeated three times. Data are expressed as the percentage of total cells/field \pm SEM.

HPLC determination of glutamate concentration. Samples of incubation solution were collected at the end of the OGD period, a time at which LDH efflux was not significantly different from control values, thus allowing us to study glutamate release caused by OGD and excluding the efflux of this excitatory amino acid attributable to damaged membranes. Analysis of glutamate in each sample was performed by HPLC with fluorimetric detection (Binary LC Pump 250 and Fluorescence Detector LC 240; Perkin-Elmer) after precolumn derivatization with the o-phtalaldialdehyde procedure (Lindroth and Mopper, 1979). Derivatives were separated isocratically on a reverse phase column $(4.6 \times 150$ $\mathrm{mm} ; 5 \mu \mathrm{m}$ particle diameter; Nucleosil 100-C18) using a mobile phase consisting of sodium acetate buffer ( $0.05 \mathrm{M}, \mathrm{pH} 6.5), 20 \%$ methanol, and $2 \%$ tetrahydrofuran. The area of each peak was determined with a Perkin-Elmer Nelson Model 1020 integrator (Phoenix 8088 ROM BIOS software, version 2.52) and compared with the peak area of the corresponding external standard to determine glutamate concentration. Glutamate release is expressed as the percentage of net release induced by OGD. Basal release was below the detection limit of our assay $(0.17$ $\mathrm{nmol} / 10^{6}$ cells).

TNF- $\alpha$ determination. Soluble TNF- $\alpha$ released from cells to the incubation solution was determined by a rat TNF- $\alpha$ immunoassay (Rat TNF- $\alpha$ UltraSensitive; Biosource International, Camarillo, CA) in samples collected at 2, 4, and $6 \mathrm{hr}$ after sublethal OGD.

Western blot analysis of TACE/ADAM17 and glutamate transporters. TACE and glutamate transporter protein levels were determined in homogenates of cells collected $24 \mathrm{hr}$ after IPC, as described previously (Hurtado et al., 2002). Cells were homogenized at $4^{\circ} \mathrm{C}$ in 5 volumes of buffer containing $320 \mathrm{~mm}$ sucrose, $1 \mathrm{~mm}$ DL-dithiothreitol, $10 \mu \mathrm{g} / \mathrm{ml}$ leupeptin, $10 \mu \mathrm{g} / \mathrm{ml}$ soybean trypsin inhibitor, $2 \mu \mathrm{g} / \mathrm{ml}$ aprotinin, $0.2 \%$ Nonidet (Roche, Barcelona, Spain), $100 \mu \mathrm{M}$ 1,10-phenanthroline, and 50 $\mathrm{mm}$ Tris, $\mathrm{pH} 7.0$, at $20^{\circ} \mathrm{C}$ with $\mathrm{HCl}$ (homogenization buffer). 1,10-
Phenanthroline was included to avoid removal of the cytoplasmic domain after cell lysis by metalloproteases, very likely TACE itself (Schlöndorff et al., 2000). Samples for TACE determination were deglycosylated as described by Lammich et al. (1999). Homogenate containing $10 \mu \mathrm{g}$ of protein was loaded, and the proteins were size separated in 10\% SDSPAGE $(90 \mathrm{~mA})$. The proteins were blotted onto a PVDF membrane (Millipore, Madrid, Spain) and incubated with the following specific primary antibodies: a polyclonal anti-TACE (1:500; ProSci Inc., Poway, CA); polyclonal antibodies against EAAT1/GLAST, EAAT2/GLT-1 (1: 500; Santa Cruz Biotechnology, Santa Cruz, CA), or monoclonal antibody against EAAT3/EAAC1 (1:500 dilution; Chemicon) glutamate transporters. Proteins recognized by the antibody were revealed by an ECL kit, following the manufacturer's instructions (Amersham Pharmacia Biotech).

$\left[{ }^{3} \mathrm{H}\right]$ Glutamate uptake by cortical cultures. $\left[{ }^{3} \mathrm{H}\right]$ Glutamate uptake by cortical cultures was determined as described (De Cristóbal et al., 2002). Briefly, cultures were washed in control solution and incubated in control solution containing $3 \mu \mathrm{m}$ glutamate and $8 \mu \mathrm{Ci} / \mathrm{ml}\left[{ }^{3} \mathrm{H}\right.$ ] glutamate for $90 \mathrm{sec}$, a time at which glutamate uptake was found to proceed linearly with time. In a parallel set of experiments, cultures were incubated during the same time in a solution of the same composition but in which $\mathrm{Na}^{+}$was substituted equiosmotically by choline. At the end of the incubation, solution was collected and cells were lysed by the addition of perchloric acid $(0.3 \mathrm{M}) .\left[{ }^{3} \mathrm{H}\right]$ Glutamate uptake was calculated by subtracting the uptake in the absence of $\mathrm{Na}^{+}$from the uptake in its presence and expressed as the percentage of total $\left[{ }^{3} \mathrm{H}\right]$ glutamate.

Determination of caspase-3 activity. Caspase-3 activity was determined as an indicator of apoptosis. Caspase- 3 activity was measured in a fluorometric assay by measuring the extent of cleavage of the fluorescent peptide substrate with a commercial kit (Molecular Probes, Eugene, OR), following manufacturer's recommendations. The fluorescence of the rhodamine 110-labeled caspase-3 product was determined in a fluorescence microplate reader (Fluoroskan Ascent FL; Labsystems, Helsinki, Finland)

Chemicals and statistical analyses. BB-3103 [N1-(2,2-dimethyl-1methylcarbamoyl-propyl)-N4-hydroxy-2-isobutyl-3-(thiophene-2sulfonyl-methyl)-succinamide] (Ancuta et al., 1997; Middelhoven et al., 1997) was kindly supplied by British Biotech, and other chemicals were obtained from Sigma (Spain), or as indicated in the text. Results are expressed as mean \pm SEM of the indicated number of experiments; statistical analysis involved one-way ANOVA (or the Kruskal-Wallis test when the data were not normally distributed), followed by individual comparisons of means (Student-Newman-Keuls or Dunn's method when the data were not normally distributed). $p<0.05$ was considered statistically significant.

\section{Results}

\section{Effect of sublethal OGD or TNF- $\alpha$ pretreatment on OGD-induced cell death and effect of the TACE inhibitor BB3103 and anti-TNF- $\alpha$}

OGD caused cell death as shown by an increase in LDH efflux to the incubation medium $(n=12)$ (Fig. $1 E)$ and by morphological alterations such as neurite fragmentation and soma vacuolization (Fig. $1 B)(100 \%$ vs $29.0 \pm 5.9 \%$ viable cells in control and OGD, respectively; $n=6 ; p<0.05)$. Prior exposure to sublethal OGD (IPC) did not alter cell viability by itself $(7.2 \pm 0.8 \%$ vs $6.0 \pm$ $0.5 \% \mathrm{LDH}$ release in IPC and control, respectively; $n=12 ; p>$ $0.05)$ but decreased lethal OGD-induced LDH release measured $24 \mathrm{hr}$ after the insult (Fig. $1 \mathrm{E}$ ) and caused neuroprotection when observed under phase-contrast microscopy at this time (Fig. $1 C$; $81.8 \pm 16.0 \%$ viable cells; $n=6 ; p<0.05$ vs OGD cells). OGDinduced cell death was decreased also in cells that had been pretreated with TNF- $\alpha 24 \mathrm{hr}$ before the ischemic insult (Fig. 1E) $(n=24 ; p<0.05)$.

The TACE inhibitor BB3103 (0.5-1 $\mu \mathrm{M})$ concentrationdependently inhibited the protective effect caused by sublethal OGD, and blocking concentrations of anti-TNF- $\alpha(2 \mu \mathrm{g} / \mathrm{ml})$ had 

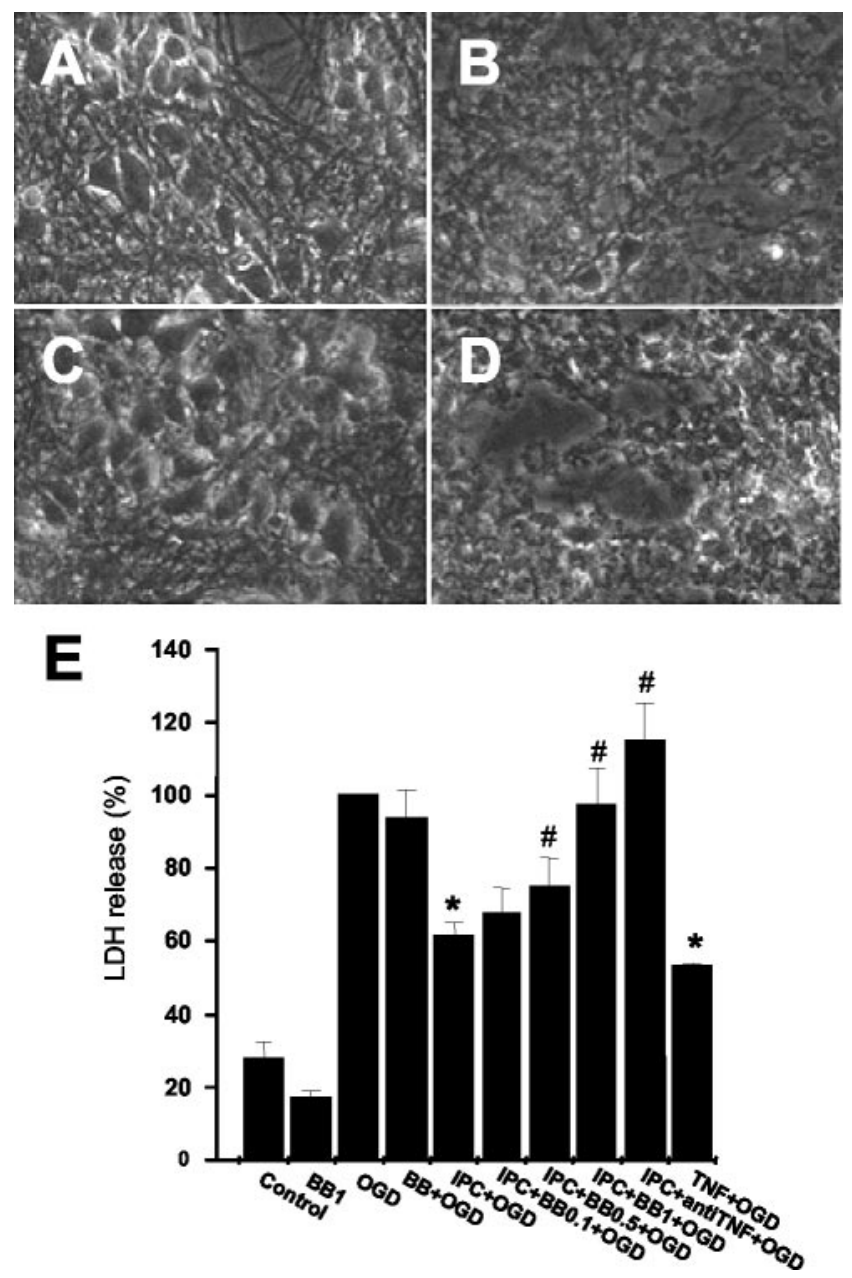

Figure 1. Effect of IPC by prior sublethal $O G D$ on cell viability after lethal $O G D$ and the role of the TACE/ADAM17-TNF- $\alpha$ pathway. Phase- contrast micrographs of control rat cortical cultures $(A)$ and after its exposure to lethal OGD $(B)$. OGD-induced cell death was prevented by prior exposure to IPC $(C)$, an effect that was inhibited by incubation of rat cortical cultures with anti-TNF- $\alpha$ antibody after IPC (D). E, Effect of IPC or TNF- $\alpha$ on LDH release from rat cortical cultures after OGD. The effect of the TACE inhibitor BB3103 (BB; 0.1-1 $\mu \mathrm{m}$ ) or anti-TNF- $\alpha$ antibody (anti-TNF; $2 \mu \mathrm{g} / \mathrm{ml}$ ) is shown. LDH is expressed as the percentage of total LDH and plotted as the percentage of $L D H$ release after $0 G D(67 \pm 6 \%$ of total $L D H ; n=12)$. Data are mean \pm SEM; $n=12 ;{ }^{*} p<0.05$ versus 0 GD; ${ }^{*} p<0.05$ versus IPC +0 GD.

a similar effect (Fig. $1 D: 32.9 \pm 1.0$ and $50.7 \pm 5.7 \%$ viable cells after BB3103 or anti-TNF- $\alpha$ treatment, respectively; $n=6 ; p<$ 0.05 vs IPC; Fig. $1 E: n=12$; $p<0.05)$. BB3103 $(1 \mu \mathrm{M})$ did not affect the protective effect caused by TNF- $\alpha$ pretreatment (56 \pm $5 \%$ of OGD-induced LDH release; $n=6 ; p>0.05$ ). In addition, none of the compounds used affected cell viability in control cells.

Effect of IPC on TACE expression in mixed cortical cultures Western blot analysis revealed the presence of two TACEimmunopositive bands (Fig. $2 \mathrm{~A}$ ), very likely corresponding to the precursor and mature forms of TACE, in rat cortical cultures. Its exposure to sublethal OGD induced an increase in protein levels of both TACE bands (Fig. 2A).

\section{Effect of IPC on TNF- $\alpha$ levels and effect of inhibition} of TACE

Exposure to IPC caused an increase in TNF- $\alpha$ levels in the incubation medium 2, 4, and $6 \mathrm{hr}$ after IPC when compared with

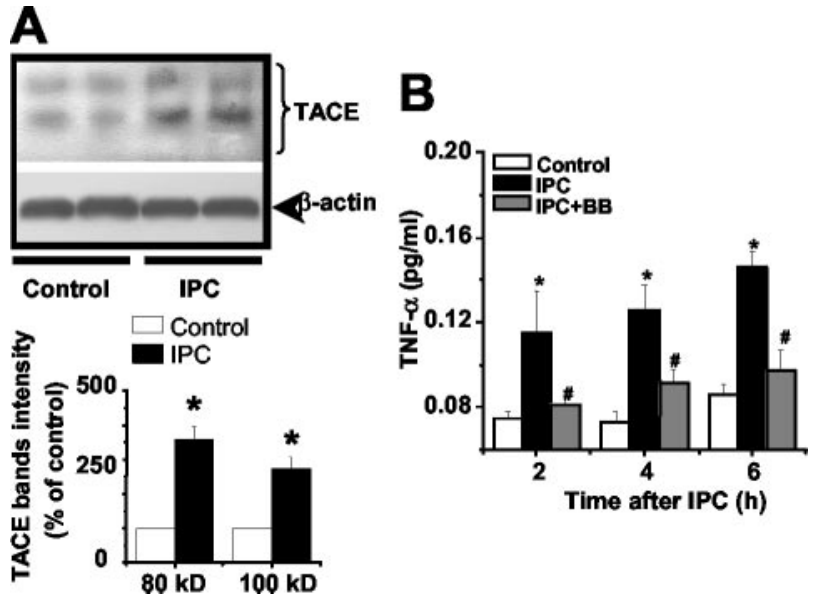

Figure 2. Characterization of the TACE-TNF- $\alpha$ pathway in rat cortical cultures after IPC. A, Effect of IPC on the levels of TACE/ADAM17 protein in rat cortical cultures determined by Western blot analysis in cell homogenates. Bottom, Densitometric analysis of bands. Data are mean $\pm \mathrm{SEM} ; n=4 ;{ }^{*} p<0.05$ versus control. $B$, TNF- $\alpha$ levels in the incubation solution of rat cortical cultures in control conditions or 2, 4, and $6 \mathrm{hr}$ after sublethal $O G D$, in the absence or presence of the TACE inhibitor BB3103 $(1 \mu \mathrm{M})$. TNF- $\alpha$ was determined by ELISA (see Materials and Methods). Data are mean \pm SEM; $n=6 ;{ }^{*} p<0.05$ versus control; ${ }^{*} p<0.05$ versus 0 GD.

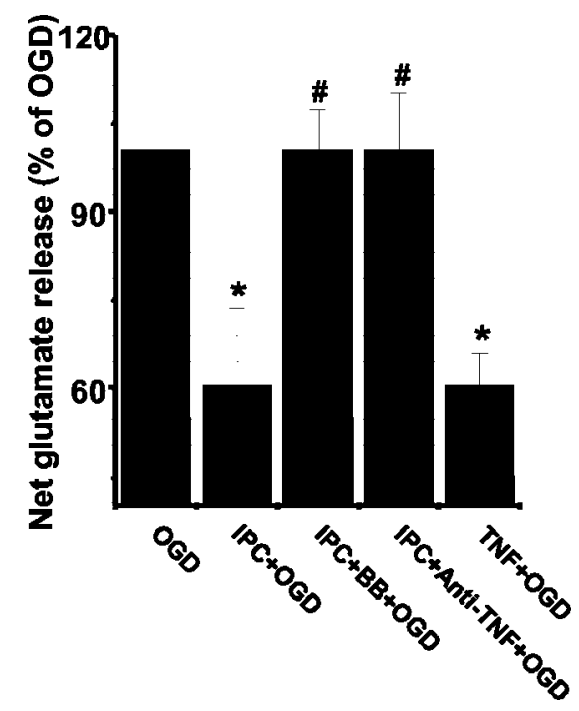

Figure 3. Effect of prior sublethal $O G D(I P C)$ on glutamate release after $O G D$ and the role of TACE-TNF- $\alpha$ pathway. IPC-induced inhibition of OGD glutamate release is inhibited by the TACE inhibitor BB3103 (1 $\mu \mathrm{m}$; BB) or anti-TNF- $\alpha$ antibody ( $2 \mu \mathrm{g} / \mathrm{ml}$; anti-TNF) and is mimicked by TNF- $\alpha$ incubation ( $10 \mathrm{pg} / \mathrm{ml}$; TNF). Data are mean \pm SEM; $n=12 ;{ }^{*} p<0.05$ versus OGD; $\# p<0.05$ versus IPC +0 GD.

control cultures $(p<0.05)$ (Fig. $2 B)$. Treatment with BB-3103 (1 $\mu \mathrm{M})$, a selective inhibitor of TACE activity, inhibited TNF- $\alpha$ increase induced by IPC (Fig. 2B).

Effect of IPC on OGD-induced glutamate release

OGD caused the release of the excitatory amino acid glutamate from rat cortical cultures $\left(1.49 \pm 0.19 \mathrm{nmol} / 10^{6}\right.$ cells; $\left.n=12\right)$ when compared with the control group (below detection limit; see Materials and Methods) (Fig. 3). Exposure to IPC caused a significant inhibition on the increased levels of glutamate after OGD (Fig. 3). Both the TACE inhibitor BB3103 and anti-TNF- $\alpha$ antibody reversed the inhibitory effect of IPC on OGD-induced glutamate release (Fig. 3). Incubation with BB3103 alone did not 
affect OGD-induced glutamate release $\left(1.53 \pm 0.21 \mathrm{nmol} / 10^{6}\right.$ cells; $n=12 ; p>$ $0.05)$. In addition, preincubation with TNF- $\alpha$ by itself caused an inhibition of OGD-induced glutamate release (Fig. 3).

\section{Effect of sublethal OGD or TNF- $\alpha$}

pretreatment on $\left[{ }^{3} \mathrm{H}\right]$ glutamate uptake by rat mixed cortical cultures

$\left[{ }^{3} \mathrm{H}\right]$ Glutamate uptake in mixed control cultures $(2.47 \pm 0.06 \mu \mathrm{Ci} / \mathrm{mg}$ protein; $n=$ 8) (Fig. 4A) was significantly increased in those cultures that had been exposed to IPC or to TNF- $\alpha 24$ hr before (Fig. $4 A$ ). IPC-induced increase in uptake was prevented by the TACE inhibitor BB3103 or an anti-TNF- $\alpha$ antibody (Fig. $4 A$ ).

Effect of sublethal OGD or TNF- $\alpha$ pretreatment on glutamate transporters expression in mixed cultures

Western blot analysis showed that EAAT1/ GLAST, EAAT2/GLT-1, and EAAT3/ EAAC1 glutamate transporters are expressed in rat cortical cultures (Fig. 4B). Exposure to sublethal OGD caused an increase in the expression of EAAT2 and EAAT3, but not EAAT1, glutamate transporters (Fig. 4 B). Treatment with BB3103 or anti-TNF- $\alpha$ antibody prevented the effect of sublethal OGD on EAAT3 expression but not on EAAT2 expression (Fig. 4B).

Effect of IPC on OGD-induced cell death in cocultures

Prior exposure to IPC decreased lethal OGD-induced LDH release measured 24 hr after the insult in neurons-astrocytes cocultures $(100 \%$ vs $42.8 \pm 6.8 \%$ in OGD and IPC-exposed cells, respectively; $n=12$; $p<0.05$ ) and caused neuroprotection when observed under phase-contrast microscopy at this time $(30.1 \pm 4.1 \%$ vs $87.6 \pm 8.2 \%$ viable cells in OGD and IPC-exposed cells, respectively; $n=6 ; p<0.05$ ).

Effect of sublethal OGD or TNF- $\alpha$ pretreatment on neuronal and astrocytic $\left[{ }^{3} \mathrm{H}\right]$ glutamate uptake after coculture

$\left[{ }^{3} \mathrm{H}\right]$ Glutamate uptake in pure neuronal control cultures $(1.87 \pm 0.18 \mu \mathrm{Ci} / \mathrm{mg}$ protein; $n=8$ ) (Fig. $5 A$ ) was significantly increased in those cultures that had been exposed to IPC or to TNF- $\alpha 24 \mathrm{hr}$ before in the coculture system (Fig. 5A). In contrast, $\left[{ }^{3} \mathrm{H}\right]$ glutamate uptake by control astrocytes $(2.51 \pm 0.24 \mu \mathrm{Ci} / \mathrm{mg}$ protein; $n=8)$ (Fig. 5A) was not affected by exposure to IPC and was decreased after TNF- $\alpha$ treatment in the coculture setup (Fig. 5A).
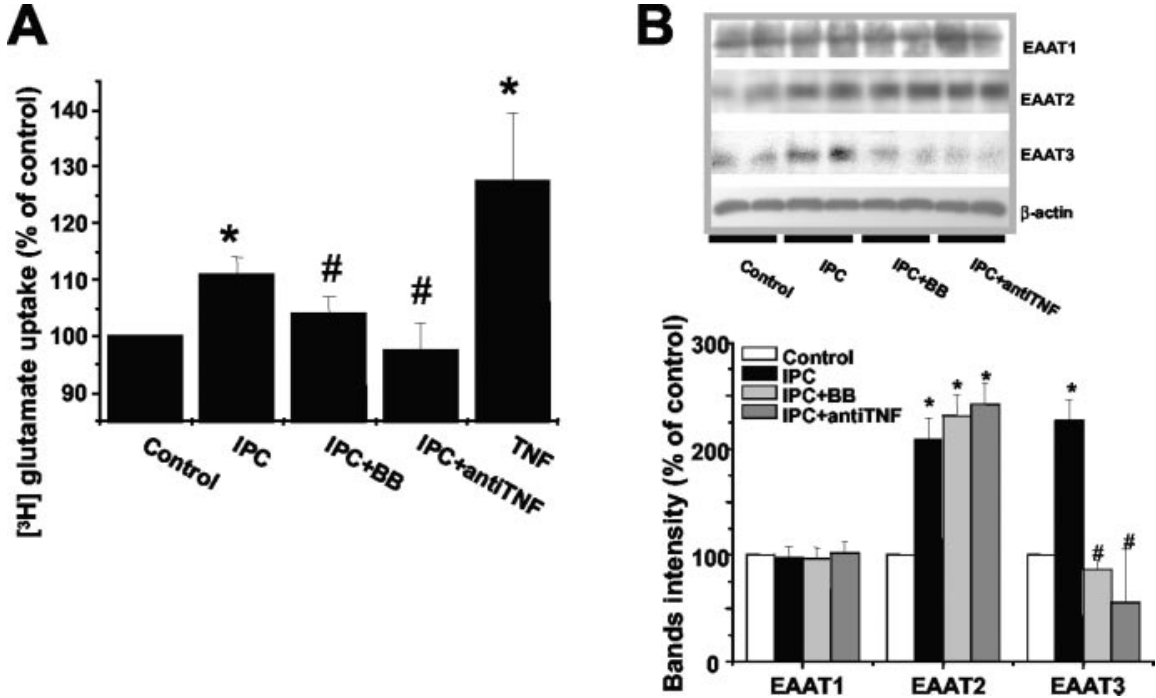

Figure 4. $\quad A,\left[{ }^{3} \mathrm{H}\right] \mathrm{Glutamate}$ uptake in control cultures (control) and after exposure to sublethal $0 \mathrm{GD}$, either in the absence $(\mathrm{IPC})$ or in the presence of BB3103 (1 $\mu \mathrm{m}$; IPC + BB) or anti-TNF- $\alpha$ antibody $(2 \mu \mathrm{g} / \mathrm{ml} ; \mathrm{IPC}+$ antiTNF). The effect of TNF- $\alpha$ incubation (10 pg/ml; TNF) is shown. B, Western blot analysis of EAAT1/GLAST, EAAT2/GLT-1, and EAAT3/EAAC1 glutamate transporters in homogenates from control cultures (control) or after exposure to sublethal OGD, either in the absence (IPC) or in the presence of BB3103 (1 $\mu \mathrm{m} ; \mathrm{IPC}+\mathrm{BB})$ or anti-TNF- $\alpha$ antibody ( $2 \mu \mathrm{g} / \mathrm{ml} ; \mathrm{IPC}+$ antiTNF). Data are mean $\pm \mathrm{SEM} ; n=8 ;{ }^{*} p<0.05$ versus control; ${ }^{\sharp} p<0.05$ versus IPC.

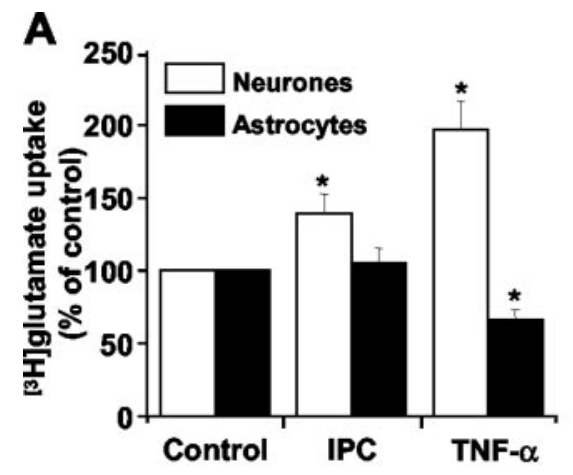

B
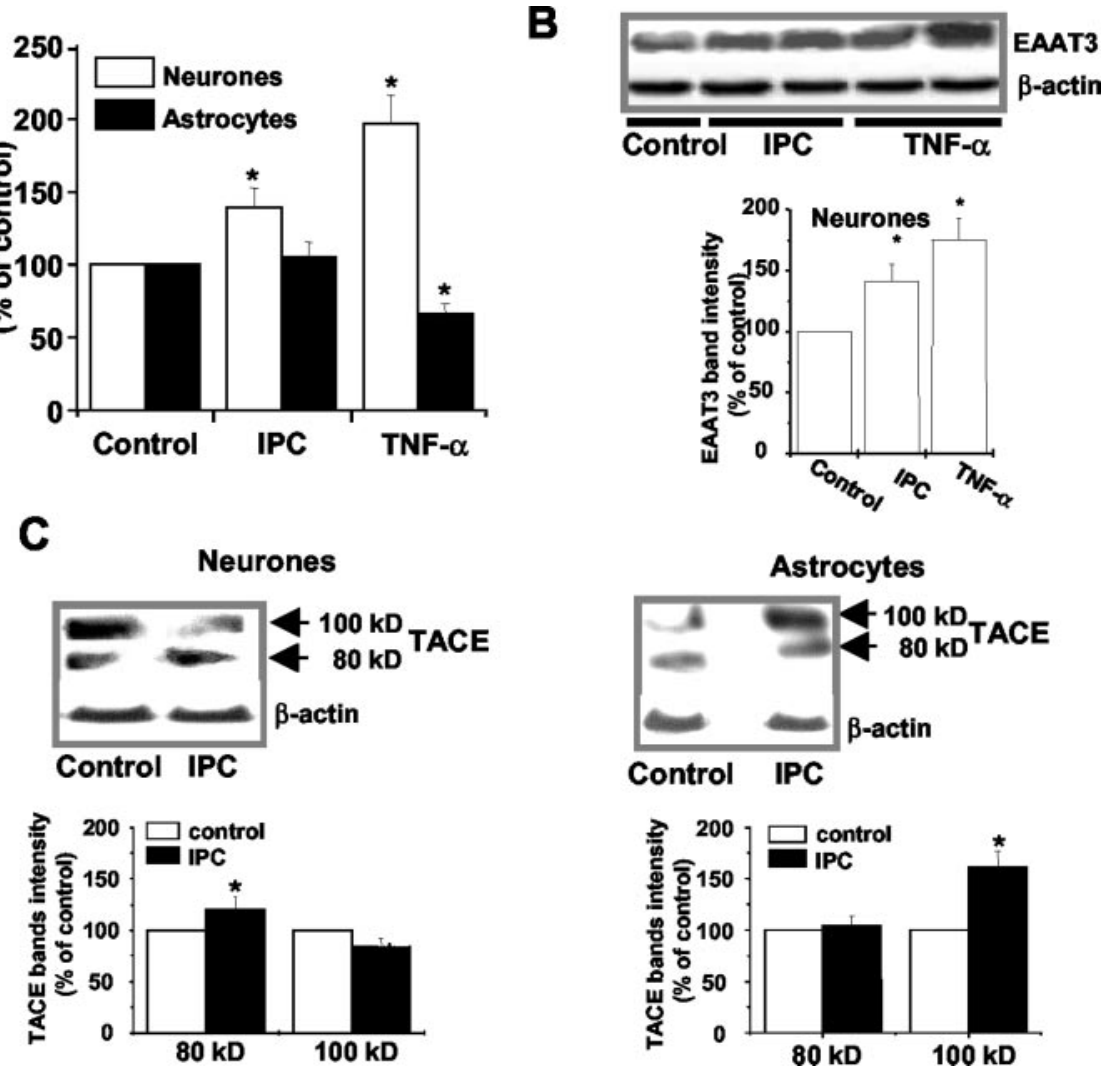

Figure 5. $\quad A,\left[{ }^{3} \mathrm{H}\right]$ Glutamate uptake by control pure neuronal $(\square)$ or astrocytes cultures $(\square)$ and after exposure to sublethal OGD (IPC) or TNF- $\alpha(10 \mathrm{pg} / \mathrm{ml})$. Data are mean $\pm \mathrm{SEM} ; n=8 ;{ }^{*} p<0.05$ versus control. $B$, Western blot analysis of EAAT3/EAAC1 glutamate transporter in homogenates from pure neuronal cultures in control conditions and after exposure to IPC or TNF- $\alpha$. Bottom, Densitometric analysis of bands. Data are mean \pm SEM; $n=4 ;{ }^{*} p<0.05$ versus control. C, Western blot analysis of TACE in homogenates from control cultures (control) or after exposure to sublethal OGD (IPC) in neurons (left) and astrocytes (right). Bottom, Densitometric analysis of bands. Data are mean $\pm \mathrm{SEM} ; n=4 ;{ }^{*} p<0.05$ versus control. 


\section{Effect of sublethal OGD or TNF- $\alpha$ pretreatment on EAAT3 glutamate transporter and TACE expression in neurones and astrocytes after coculture}

Western blot analysis showed that EAAT3/EAAC1 glutamate transporter, which is expressed in pure rat cortical neurons as shown by an immunopositive band of $57 \mathrm{kDa}$ (Fig. $5 B$ ), had its levels increased after exposure to IPC or TNF- $\alpha$ (Fig. $5 B$ ). This band was not detected in the astrocytic lysates. However, an EAAT3-immunopositive band with an apparent electrophoretic mobility of $\sim 180 \mathrm{kDa}$ was found in astrocytes lysates, the expression of which did not change after IPC (data not shown).

Both mature TACE as well as its precursor were found in both neurons and astrocytes (Fig. 5C). After IPC in the coculture system, neuronal TACE protein showed an increase in the levels of mature TACE, in parallel to a decrease in the precursor (Fig. 5C). In contrast, IPC induced an increase in the levels of the precursor of TACE in the astrocytic cultures (Fig. 5C).

\section{Effect of sublethal OGD on the apoptotic parameter caspase-3 activity after OGD}

At $24 \mathrm{hr}$, caspase- 3 activity found in control cells was $5.5 \pm 0.6$ $\mathrm{pmol} / \mathrm{min} / \mathrm{mg}$ protein $(n=6)$. After OGD, caspase- 3 activity in the remaining cells was $4.0 \pm 0.2 \mathrm{pmol} / \mathrm{min} / \mathrm{mg}$ protein, a value that was increased in cells that had been exposed to prior sublethal OGD $(5.0 \pm 0.4 \mathrm{pmol} / \mathrm{min} / \mathrm{mg}$ protein; $n=6 ; p<0.05)$.

\section{Discussion}

We have recently demonstrated the presence of TACE protein in rat CNS. In addition, we have shown, using in vitro models, that TACE is upregulated after ischemic brain damage and that the increase in TACE expression contributes to a rise in TNF- $\alpha$ and a subsequent neuroprotective effect after excitotoxic stimuli (Hurtado et al., 2001, 2002). Moreover, we have recently provided evidence of TACE upregulation after IPC, its major role in TNF- $\alpha$ shedding in this setting, and its neuroprotective role in ischemic tolerance (Cárdenas et al., 2002). We have now investigated the mechanisms implicated in TACE-induced ischemic tolerance by using rat cortical cultures exposed to sublethal OGD as a preconditioning maneuver.

IPC by sublethal OGD caused ischemic tolerance to subsequent lethal OGD exposures, as previously reported (Bruer et al., 1997; Grabb and Choi, 1999, Liu et al., 2000). Analysis of TACE protein by Western blot demonstrates its presence in control cortical cultures, consistently with the demonstration of TACE mRNA in rat and mouse adult brain (Kärkkäinen et al., 2000) and with our work demonstrating the presence of TACE protein in rat CNS (Hurtado et al., 2001; Cárdenas et al., 2002; Hurtado et al., 2002; Madrigal et al., 2002). Moreover, our present results indicate that TACE expression is increased in cultures exposed to IPC, also in agreement with our previous data showing TACE upregulation after IPC in in vivo models of cerebral ischemia (Cárdenas et al., 2002).

Increased expression of TACE after IPC raises the question of its role in TNF- $\alpha$ release. Our results show that IPC causes the release of soluble TNF- $\alpha$, an effect that is inhibited by the hydroxamate-based compound BB3103, suggesting that this release results predominantly from pro-TNF- $\alpha$ shedding by TACE/ ADAM17. Although other proteases may cleave pro-TNF- $\alpha$ (Lammich et al., 1999), hydroxamate-based compounds are more potent against TACE, a fact that has been used to distinguish between TACE effect and that of other proteases (Parvathy et al., 1998; Hooper et al., 2000). An increased pro-TNF- $\alpha$ synthesis (Wang et al., 2000) is likely to be involved as well.
It is well known that TNF- $\alpha$, which is expressed or released after ischemia (Liu et al., 1994), contributes to the damaging effects of this condition but also possesses neuroprotective effects (for review, see Barone and Feuerstein, 1999; Shohami et al., 1999; Del Zoppo et al., 2000; Hallenbeck, 2002). We now show that TACE-induced TNF- $\alpha$ release participates in the development of ischemic tolerance, because incubation of IPC-exposed cells with the TACE inhibitor BB3103 or an anti-TNF- $\alpha$ antibody is able to inhibit IPC-induced neuroprotection. These data are in agreement with those showing that TNF- $\alpha$ pretreatment induces protective effects against focal ischemia (Nawashiro et al., 1997) and that expression of TNF- $\alpha$ mRNA is augmented after preconditioning (Wang et al., 2000). Other reports have also shown the protective role of TNF- $\alpha$ in IPC in animals both in vitro and in vivo (Liu et al., 2000; Cárdenas et al., 2002; Ginis et al., 2002) and in humans (Castillo et al., 2003).

We then decided to pursue some of the mechanisms involved after activation of the TACE-TNF- $\alpha$ pathway. Glutamate is known to play a predominant role in the pathogenesis of ischemic brain injury: this excitatory amino acid is released in high concentrations in the core of the cerebral infarction and in the penumbral tissue, where it overactivates glutamate receptors leading to a massive influx of calcium that activates a variety of catabolic processes that subsequently produce cell death (Choi and Rothman, 1990; Castillo et al., 1996). As a possible IPCinduced effect, we tested the correlation between IPC-induced tolerance and OGD-induced glutamate release. Our results indicate that OGD-induced increase in extracellular glutamate is lower in IPC-exposed cultures, an effect blocked by BB3103 and anti-TNF- $\alpha$ and mimicked by preincubation with TNF- $\alpha$. In agreement with our results, previous reports have shown that glutamate release is inhibited in rat brain cortical slices preconditioned by exposure to hypoxia/hypoglycemia (Johns et al., 2000), as well as in murine cortical neurons preconditioned with $\mathrm{KCl}$ (Grabb et al., 2002).

Glutamate transporters in neurons and glia remove glutamate from extracellular space, thereby helping to terminate glutamatergic synaptic transmission and to prevent the extracellular glutamate concentration from rising to neurotoxic values (Takahashi et al., 1997; Maragakis and Rothstein, 2001). Glutamate transporters are, therefore, a plausible molecular target of preconditioning maneuvers. To date, five high-affinity, sodium-dependent glutamate transporters have been cloned from mammalian tissue (Seal and Amara, 1999): EAAT1/GLAST and EAAT2/GLT-1 are localized primarily in astrocytes, EAAT3/EAAC1 and EAAT4 are distributed in neuronal membranes, and EAAT5 is retinal. We have evaluated the involvement of transporter regulation by studying (1) cellular glutamate uptake and (2) whole expression of the main transporters EAAT1, EAAT2, and EAAT3 after IPC. First, our data show that $\left[{ }^{3} \mathrm{H}\right]$ glutamate uptake is increased in cells exposed to IPC or TNF- $\alpha$. Moreover, IPC-induced increase in uptake is reduced by prior treatment with the TACE inhibitor BB3103 or anti-TNF- $\alpha$ antibody. Western blot analysis showed that EAAT1/GLAST, EAAT2/GLT-1, and EAAT3/EAAC1 glutamate transporters are expressed in rat cortical cultures, consistent with the mixed population of neurons and glial cells present in this preparation. More interestingly, that increased glutamate uptake is involved in IPC-induced neuroprotection is further confirmed by our results demonstrating that cellular expression of EAAT2/GLT-1 and EAAT3, but not that of EAAT1/ GLAST, is increased in IPC-exposed cells. Interestingly, the IPCinduced increase in EAAT3 expression is inhibited by BB3103 and anti-TNF- $\alpha$. In contrast, the IPC-induced increase in EAAT2 does not respond to the interference with TACE-TNF- $\alpha$ pathway. 
An interesting question regards the cells responsible for increased glutamate uptake after preconditioning. Thus, we have used pure populations of neurons and astrocytes, the major cell types in our preparation, and exposed them together to preconditioning treatments in a coculture setup, allowing us to study subsequently glutamate uptake and protein expression in each population. Glutamate uptake was consistently increased in neurons exposed to both preconditioning stimuli. Interestingly, astrocytic uptake was unaffected by sublethal OGD and decreased after exposure to TNF- $\alpha$. The neuronal expression of EAAT3, the glutamate transporter that seems to be the target of the TACETNF- $\alpha$ pathway, showed a profile in agreement with the uptake experiments. In astrocytes, an EAAT3-immunopositive band was detected, but of a different molecular weight. These results strongly suggest that IPC induces an increase in neuronal EAAT3 transporter expression that accounts for at least part of the neuroprotection found.

We have also found that both neurons and astrocytes express TACE protein in both mature and precursor forms. Interestingly, our data show that IPC induces a different regulation of TACE in each cell type: in neurons, there is an increase in mature TACE and a decrease in its precursor, consistent with a regulation by increased processing; in contrast, in astrocytes, IPC induces an increase in the expression of the precursor form, suggesting a regulation at the transcriptional level that deserves additional study. These results suggest that both a paracrine and an autocrine protective mechanism may take place having as the final target the neuronal expression of EAAT3.

A change in transporter expression of transporters does not clarify what the consequence is, because reversed operation of neuronal glutamate transporters accounts for most glutamate release induced by severe ischemia (Jabaudon et al., 2000; Rossi et al., 2000). However, it is not clear the transporter subtype involved, and antisense studies have suggested that reversal of the neuronal EAAT3/EAAC1 does not contribute to glutamate release after ischemia (Rao et al., 2001). Although this study focused on the TACETNF- $\alpha$-EAAT3 pathway, additional studies are needed to clarify the regulation of the EAAT2 trasporter by IPC.

To our knowledge, this is the first report of an increased expression of glutamate transporters after IPC. TNF- $\alpha$ has been shown to inhibit glutamate uptake systems in astrocytes (Fine et al., 1996; Ye and Sontheimer, 1996; Szymocha et al., 2000), apparently at a post-translational level. In addition, TNF- $\alpha$ has been shown to upregulate either expression or function of transporters of different substrates (Durante et al., 1996; Gill et al., 1996; Irie et al., 1997; Mossner et al., 1998, Mochizuki et al., 2002).

Basal apoptosis measured as caspase- 3 activity was slightly decreased by OGD at $24 \mathrm{hr}$, and it returned to control values in preconditioned cells, an effect likely caused by a higher number of cells present that did not undergo early necrosis. This suggests that the neuroprotective effect of preconditioning is exerted mainly on the early necrosis.

In summary, our data show that IPC increases the expression of the glutamate transporters EAAT2 and EAAT3, an effect that mediates ischemic tolerance by decreasing excitotoxicity attributable to OGD-induced increase in extracellular glutamate in rat cortical cultures. We also demonstrated that increased glutamate transport results partly from TACE upregulation and subsequent increase in TNF- $\alpha$. Thus, elucidation of mechanisms that regulate the acquisition of brain tolerance could guide efforts to develop effective measures or safe pharmacological preconditioning agents to protect the brain or reduce ischemic injury.

\section{References}

Ancuta P, Fahmi H, Pons JF, Le Blay K, Chaby R (1997) Involvement of the membrane form of tumour necrosis factor- $\alpha$ in lipopolysaccharideinduced priming of mouse peritoneal macrophages for enhanced nitric oxide response to lipopolysaccharide. Immunology 92:259-266.

Barone FC, Feuerstein GZ (1999) Inflammatory mediators and stroke: new opportunities for novel therapeutics. J Cereb Blood Flow Metab 19:819-834.

Barone FC, White RF, Spera PA, Ellison J, Currie RW, Wang X, Feurstein GZ (1998) Ischemic preconditioning and brain tolerance. Stroke 29:1937-1951.

Blondeau N, Widmann C, Lazdunski M, Heurteaux C (2001) Activation of the nuclear factor- $\kappa \mathrm{B}$ is a key event in brain tolerance. J Neurosci 21:4668-4677.

Bruer U, Weih MK, Isaev NK, Meisel A, Ruscher K, Bergk A, Trendelenburg G, Wiegand F, Victorov IV, Dirnagl U (1997) Induction of tolerance in rat cortical neurones: hypoxic preconditioning. FEBS Lett 414:117-121.

Cárdenas A, Moro MA, Leza JC, O'Shea E, Davalos A, Castillo J, Lorenzo P, Lizasoain I (2002) Up-regulation of TACE/ADAM17 after ischemic preconditioning is involved in brain tolerance. J Cereb Blood Flow Metab 22:1297-1302.

Castillo J, Dávalos A, Naveiro J, Noya M (1996) Neuroexcitatory amino acids and their relationship to infarct size and neurological deficit in ischemic stroke. Stroke 27:1060-1065.

Castillo J, Moro MA, Blanco M, Leira R, Serena J, Lizasozin I, Davzlos A (2003) The release of tumor necrosis factor-alpha is associated with ischemic tolerance in human stroke. Ann Neurol 54:811-819.

Choi DW, Rothman SM (1990) The role of glutamate neurotoxicity in hypoxic-ischaemic neuronal death. Annu Rev Neurosci 13:171-182.

De Cristóbal J, Cardenas A, Lizasoain I, Leza JC, Fernandez-Tomé P, Lorenzo P, Moro MA (2002) Inhibition of glutamate release via recovery of ATP levels accounts for a neuroprotective effect of aspirin in rat cortical neurons exposed to oxygen-glucose deprivation. Stroke 33:261-267.

Del Zoppo G, Ginis I, Hallenbeck JM, Iadecola C, Wang X, Feuerstein GZ (2000) Inflammation and stroke: putative role for cytokines, adhesion molecules and iNOS in brain response toischemia. Brain Pathol 10:95-112.

Durante W, Liao L, Cheng K, Schafer AI (1996) Selective induction of a cationic amino acid transporter by tumor necrosis factor-alpha in vascular endothelium. Prog Assoc Am Phys 108:356-361.

Fine SM, Angel RA, Perry SW, Epstein LG, Rothstein JD, Dewhurst S, Gelbard HA (1996) Tumor necrosis factor $\alpha$ inhibits glutamate uptake by primary human astrocytes. J Biol Chem 271:15303-15306.

Fiorucci S, Antonelli E, Migliorati G, Santucci L, Morelli O, Federici B, Morelli A (1998) TNF- $\alpha$ processing enzyme inhibitors prevent aspirininduced TNF- $\alpha$ release and protect against gastric mucosal injury in rats. Aliment Pharmacol Ther 12:1139-1153.

Gill DJ, Low BC, Grigor MR (1996) Interleukin-1 beta and tumor necrosis factor-alpha stimulate the cat-2 gene of the L-arginine transport in cultured vascular smooth muscle cells. J Biol Chem 271:11280-11283.

Ginis I, Jaiswal R, Klimanis D, Liu J, Geenspon J, Hallenbeck JM (2002) TNF- $\alpha$-Induced tolerance to ischaemic injury involves differential control of NF- $\kappa \mathrm{B}$ transactivation: the role of NF- $\kappa \mathrm{B}$ association with p300 adaptor. J Cereb Blood Flow Metab 22:142-152.

González-Zulueta M, Feldman AB, Klesse LJ, Kalb RG, Dillman JF, Parada LF, Dawson TM, Dawson VL (2000) Requirement for nitric oxide activation of p21(ras)/extracellular regulated kinase in neuronal ischemic preconditioning. Proc Natl Acad Sci USA 97:436-441.

Grabb MC, Choi DW (1999) Ischemic tolerance in murine cortical cell culture: critical role for NMDA receptors. J Neurosci 19:1657-1662.

Grabb MC, Lobner D, Turetsky M, Choi DW (2002) Preconditioned resistance to oxygen-glucose deprivation-induced cortical neuronal death: alterations in vesicular GABA and glutamate release. Neuroscience 115:173-183.

Hallenbeck JM (2002) The many faces of tumor necrosis factor in stroke. Nat Med 8:1363-1368.

Heurteaux C, Lauritzen I, Widmann C, Lazdunski M (1995) Essential role of adenosine, adenosine $\mathrm{A} 1$ receptors, and ATP-sensitive $\mathrm{K}^{+}$channels in cerebral ischemic preconditioning. Proc Natl Acad Sci USA 92:4666-4670.

Hooper NM, Trew AJ, Parkin ET, Turner AJ (2000) The role of proteolysis in Alzheimer's disease. Adv Exp Med Biol 477:379-390.

Hurtado O, Cárdenas A, Lizasoain I, Boscá L, Leza JC, Lorenzo P, Moro MA (2001) Up-regulation of TNF- $\alpha$ convertase (TACE/ADAM17) after 
oxygen-glucose deprivation in rat forebrain slices. Neuropharmacology 40:1094-1102.

Hurtado O, Lizasoain I, Fernández-Tomé P, Álvarez-Barrientos A, Leza JC, Lorenzo P, Moro MA (2002) TACE/ADAM17-TNF $\alpha$ pathway in rat cortical cultures after exposure to oxygen-glucose deprivation or glutamate. J Cereb Blood Flow Metab 22:576-585.

Irie K, Tsukahara F, Fujii E, Uchida Y, Yoshioka T, He WR, Shitashige M, Murota S, Muraki T (1997) Cationic amino acid transporter-2 mRNA induction by tumor necrosis factor-alpha in vascular endothelial cells. Eur J Pharmacol 339:289-293.

Jabaudon D, Scanziani M, Gähwiler BH, Gerber U (2000) Acute decrease in net glutamate uptake during energy deprivation. Proc Natl Acad Sci USA 97:5610-5615.

Johns L, Sinclair AJ, Davies JA (2000) Hypoxia/hypoglycemia-induced amino acid release is decreased in vitro by preconditioning. Biochem Biophys Res Commun 276:134-136.

Kasischke K, Ludolph AC, Riepe MW (1996) NMDA antagonists reverse increased hypoxic tolerance by preceding chemical hypoxia. Neurosci Lett 214:175-178.

Kato H, Liu Y, Araki T, Kogure K (1992) MK-801, but not anisomycin, inhibits the induction of tolerance to ischemia in the gerbil hippocampus. Neurosci Lett 139:118-121.

Kärkkäinen L, Rybnikova E, Pelto-Huikko M, Huovila APJ (2000) Metalloprotease-disintegrin (ADAM) genes are widely and differentially expressed in the adult CNS. Mol Cell Neurosci 15:547-560.

Kitagawa K, Matsumoto M, Tagaya M, Hata R, Ueda H, Niinobe M, Handa N, Fukunaga R, Kimura K, Mikoshiba K (1990) Ischemic tolerance phenomenon found in the brain. Brain Res 528:21-24.

Kirino T (2002) Ischemic tolerance. J Cereb Blood Flow Metab 22:1283-1296.

Kirino T, Tsujita Y, Tamura A (1991) Induced tolerance to ischemia in gerbil hippocampal neurons. J Cereb Blood Flow Metab 11:299-307.

Koh JY, Choi DW (1987) Quantitative determination of glutamate mediated cortical neuronal injury in cell culture by lactate dehydrogenase efflux assay. J Neurosci Methods 20:83-90.

Lammich S, Kojro E, Postina R, Gilbert S, Pfeiffer R, Jasionowski M, Haass C, Fahrenholz F (1999) Constitutive and regulated $\alpha$-secretase cleavage of Alzheimer's amyloid precursor protein by a disintegrin metalloprotease. Proc Natl Acad Sci USA 96:3922-3927.

Lindroth P, Mopper K (1979) High performance liquid chromatographic determination of subpicomole amounts of amino acids by precolumn fluorescence derivatization with o-phtaldialdehyde. Anal Chem 51:1667-1674.

Liu J, Ginis I, Spatz M, Hallenbeck JM (2000) Hypoxic preconditioning protects cultured neurons against hypoxic stress via TNF- $\alpha$ and ceramide. Am J Physiol Cell Physiol 278:C144-C153.

Liu T, Clark RK, McDonnell PC, Young PR, White RF, Barone FC, Feuerstein GZ (1994) Tumor necrosis factor-alpha expression in ischemic neurons. Stroke 25:1481-1488.

Madrigal JLM, Hurtado O, Moro MA, Lizasoain I, Lorenzo P, Castrillo A, Boscá L, Leza JC (2002) The increase in TNF- $\alpha$ levels is implicated in $\mathrm{NF}-\kappa \mathrm{B}$ activation and inducible nitric oxide synthase expression in brain cortex after immobilisation stress. Neuropsychopharmacology 26:155-163.

Maragakis NJ, Rothstein JD (2001) Glutamate transporters in neurologic diseases. Arch Neurol 58:365-370.

Mattson MP, Culmsee C, Yu Z, Camandola S (2000) Roles of NF- $\kappa$ B in neuronal survival and plasticity. J Neurochem 74:443-456.

McCarthy KD, de Vellis J (1980) Preparation of separed astroglial and oligodendroglial cell cultures from rat cerebral tissue. J Cell Biol 85:890-902.

McLaughlin BA, Hartnett KA, Erhardt KA, Legos JL, White RF, Barone FC, Aizenman E (2003) Caspase 3 activation is essential for neuroprotection in preconditioning. Proc Natl Acad Sci USA 100:715-720.

Middelhoven PJ, Ager A, Roos D, Verhoeven AJ (1997) Involvement of a metalloprotease in the shedding of human neutrophil Fc gammaRIIIB. FEBS Lett 414:14-18.

Mochizuki T, Satsu H, Shimizu M (2002) Tumor necrosis factor alpha stimulates taurine uptake and transporter gene expression in human intestinal Caco-2 cells. FEBS Lett 517:92-96.
Moncayo J, de Freitas GR, Bogousslavsky J, Altieri M, van Melle G (2000) Do transient ischemic attacks have a neuroprotective effect? Neurology 54:2089-2094.

Mossner R, Heils A, Stober G, Okladnova O, Daniel S, Lesch KP (1998) Enhancement of serotonin transporter function by tumor necrosis factor alpha but not by interleukin-6. Neurochem Int 33:251-254.

Nawashiro H, Martin D, Hallenbeck JM (1997) Inhibition of tumor necrosis factor and amelioration of brain infarction in mice. J Cereb Blod Flow Metab 17:229-232.

Ohtsuki T, Ruetzler C, Tasaki K, Hallenbeck JM (1996) Interleukin-1 mediates induction of tolerance to global ischemia in gerbil hippocampal CA1 neurons. J Cereb Blood Flow Metab 16:1137-1142.

Parvathy S, Karran EH, Turner AJ, Hooper NM (1998) The secretases that cleave angiotensin converting enzyme and the amyloid precursor protein are distinct from tumour necrosis factor- $\alpha$ convertase. FEBS Lett 431:63-65.

Rao VLR, Dogan A, Todd KG, Bowen KK, Kim B-T, Rothstein JD, Dempsey RJ (2001) Antisense knockdown of the glial glutamate transporter GLT-1, but not the neuronal glutamate transporter EAAC1, exacerbates focal cerebral ischemia-induced neuronal damage in rat brain. J Neurosci 21:1876-1883.

Ravati A, Ahlemeyer B, Becker A, Klumpp S, Krieglstein J (2001) Preconditioning-induced neuroprotection is mediated by reactive oxygen species and activation of the transcription factor nuclear factor- $\kappa \mathrm{B}$. J Neurochem 78:909-919.

Rossi DJ, Oshima T, Attwell D (2000) Glutamate release in severe brain ischaemia is mainly by reversed uptake. Nature 403:316-321.

Ruscher K, Freyer D, Karsch M, Isaev N, Megow D, Sawitzki B, Priller J, Dirnagl U, Meisel A (2002) Erythropoietin is a paracrine mediator of ischemic tolerance in the brain: evidence from an in vitro model. J Neurosci 22:10291-10301.

Sauvageot CM, Stiles CD (2002) Molecular mechanisms controlling cortical gliogenesis. Curr Opin Neurobiol 12:244-249.

Seal RP, Amara SG (1999) Excitatory amino acid transporters: a family in flux. Annu Rev Pharmacol Toxicol 39:431-456.

Shimazaki K, Ishida A, Kawai N (1994) Increase in bcl-2 oncoprotein and the tolerance to ischemia-reduced neuronal death in the gerbil in the gerbil hippocampus. Neurosci Res 20:95-99.

Schlöndorff J, Becherer JD, Blobel CP (2000) Intracellular maduration and localization of tumor necrosis factor $\alpha$ convertase (TACE). Biochem J 347:131-138.

Shohami E, Ginis I, Hallenbeck JM (1999) Dual role of tumor necrosis factor alpha in brain injury. Cytokine Growth Factor Rev 10:119-130.

Szymocha R, Akaoka H, Dutuit M, Malcus C, Didier-Bazes M, Belin MF, Giraudon P (2000) Human T-cell lymphotropic vyrus type 1-infected T lymphocytes impair catabolim and uptake of glutamate by astrocytes via Tax-1 and tumor necrosis factor alpha. J Virol 74:6433-6441.

Takahashi M, Billups B, Rossi D, Sarantis M, Hamann M, Attwell D (1997) The role of glutamate transporters in glutamate homeostasis in the brain. J Exp Biol 200:401-409.

Toyoda T, Kassell NF, Lee KS (1997) Induction of ischaemic tolerance and antioxidant activity by brief focal ischaemia. NeuroReport 8:847-851.

Trendelenburg G, Prass K, Priller J, Kapinya K, Polley A, Muselmann C, Ruscher K, Kannbley U, Schmitt AO, Castell S, Wiegand F, Meisel A, Rosenthal A, Dirnagl U (2002) Serial analysis of gene expression identifies metallothionein-II as major neuroprotective gene in mouse focal cerebral ischemia. J Neurosci 22:5879-5888.

Wang X, Li X, Erhardt JA, Barone FC, Feurstein GZ (2000) Detection of TNF- $\alpha$ mRNA induction in ischemic brain tolerance by means of realtime polymerase chain reaction. J Cereb Blood Flow Metab 20:15-20.

Weih M, Kallenberg K, Bergk A, Dirnagl U, Harms L, Wernecke KD, Einhäupl KM (1999) Attenuated stroke severity after prodromal TIA. A role for ischaemic tolerance in the brain? Stroke 30:1851-1854.

Wick A, Wick W, Waltenberger W, Weller M, Dichgans J, Schulz JB (2002) Neuroprotection by hypoxic preconditioning requires sequential activation of vascular endothelial growth factor receptor and Akt. J Neurosci 22:6401-6407.

Ye ZC, Sontheimer H (1996) Cytokine modulation of glial glutamate uptake: a possible involvement of nitric oxide. NeuroReport 7:2181-2185. 